\title{
Energia líquida e ractopamina para leitoas em terminação sob altas temperaturas ambientais
}

\author{
Net energy and ractopamine to finishing gilts under high temperature environment
}

\section{Mariana Souza de Moura ${ }^{\mathrm{I}}$ Charles Kiefer ${ }^{\mathrm{II}}$ Camilla Mendonça Silva ${ }^{\mathrm{I}}$ Alexandre Pereira dos Santos ${ }^{\mathrm{I}}$ Caiki Calepso Fantini ${ }^{I}$ Lúcia dos Santos Lucas ${ }^{\mathrm{I}}$}

\section{RESUMO}

\begin{abstract}
O objetivo do trabalho foi avaliar níveis de energia líquida (EL) e ractopamina na dieta de leitoas em terminação sob altas temperaturas ambientais $\left(29,5 \pm 2,3^{\circ} \mathrm{C}\right)$. Foram

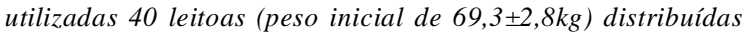
no delineamento de bloco ao acaso em esquema fatorial $2 \times 4$ (0 e 20ppm de ractopamina e 2.300; 2.424; 2.548 e $2.668 \mathrm{kcal}$ de $E L \mathrm{~kg}^{-1}$ de ração), com cinco repetições de um animal cada. Houve interação $(P<0,05)$ entre EL e ractopamina, sendo que a inclusão de $20 \mathrm{ppm}$ em dietas com 2.548 e $2.668 \mathrm{kcal}$ reduziu $(P<0,05)$ a espessura de toucinho e aumentou $(P<0,05)$ a percentagem de carne magra das carcaças. A ractopamina melhorou $(P<0,05)$ a conversão alimentar e a quantidade de carne magra nas carcaças $(P<0,05)$, independente dos níveis de EL. Concluiu-se que a ractopamina na dose de 20ppm propicia benefícios no desempenho e características de carcaça de leitoas sob estresse térmico e que esse efeito é mais positivo em dietas contendo níveis energéticos mais elevados $(2.548 e$ $2.668 \mathrm{kcal}$ de $E L)$.
\end{abstract}

Palavras-chave: aditivos, ambiente térmico, carcaça, desempenho.

\section{ABSTRACT \\ The objective of this paper was to assess net energy $(N E)$ levels and ractopamine in the diet of finishing gilts maintained under high temperature environment $\left(29.5 \pm 2.3^{\circ} \mathrm{C}\right)$. Forty gilts were used, with initial weight of $69.3 \pm 2.8 \mathrm{~kg}$, distributed in a randomized block design, in a factorial scheme $2 \times 4$ (0 and 20ppm of ractopamine; and 2,300; 2,424; 2,548 and 2,668kal/kg $\mathrm{NE} \mathrm{kg}^{-1}$ of feed), and five replications and one animal each. There was interaction $(P<0.05)$ between $N E$ levels and ractopamine, and the inclusion of $20 \mathrm{ppm}$ of ractopamine in the diets containing 2,548 and 2,668kcal reduced $(P<0.05)$ backfat thickness and increased $(P<0.05)$}

the percentage of lean meat of carcasses. The use of ractopamine improved $(P<0.05)$ feed gain ratio and increased $(P<0.05)$ the amount of lean meat in carcasses. It was concluded that ractopamine at a dose of $20 \mathrm{ppm}$ provides benefits in performance and carcass traits of gilts under heat stress and this effect is more positive in diets containing higher energy levels $\left(2,548\right.$ and 2,668kcal of $\left.\mathrm{NE}^{-1} \mathrm{gg}^{-1}\right)$.

Key words: additive, thermal environment, carcass, performance.

\section{INTRODUÇÃO}

O controle da deposição de gordura na carcaça é uma medida necessária para melhorar o índice de bonificação das carcaças e agregar valor aos suínos produzidos (MOREIRA et al., 2007). Tem-se constatado que além de aumentar a deposição protéica, a ractopamina inibe parcialmente a lipogênese, reduzindo a deposição de gordura na carcaça (PÉREZ et al., 2006). Todavia, quando os suínos são submetidos a ambientes de alta temperatura, tendem a reduzir o consumo e perder a eficiência de utilização da energia disponível, à medida que acionam mecanismos de termoregulação para manter a homeostase térmica (KERR et al., 2003). Nas circunstâncias em que as temperaturas ambientais são elevadas e o consumo dos animais é reduzido, a inclusão de lipídios às dietas pode reduzir o incremento calórico e minimizar a redução do desempenho devido ao baixo consumo (ALMEIDA et al., 2007).

'Universidade Federal de Mato Grosso do Sul (UFMS), Campo Grande, MS, Brasil.

IIDepartamento de Zootecnia, UFMS, 79074-460,Campo Grande, MS, Brasil. E-mail: charles@ufms.br. Autor para correspondência. 
Realizou-se este trabalho com o objetivo de avaliar níveis de energia líquida e ractopamina na dieta de leitoas em terminação sob altas temperaturas ambientais.

\section{MATERIAL E MÉTODOS}

O experimento foi conduzido em câmara climática, na Universidade Federal de Mato Grosso do Sul, em Campo Grande/MS. Foram utilizadas 40 leitoas, Duroc/Pietrain x Large White/Landrace, com peso inicial de 69,3 $\pm 2,8 \mathrm{~kg}$, distribuídas em delineamento de blocos ao acaso em esquema fatorial $2 \times 4$ ( 0 e $20 \mathrm{ppm}$ de ractopamina e $2.300 ; 2.424 ; 2.548$ e $2.668 \mathrm{kcal} \mathrm{de}^{\mathrm{E} L \mathrm{~kg}^{-1}}$ de ração), com cinco repetições, sendo cada unidade experimental constituída por um animal. Na formação dos blocos, levou-se em consideração o peso inicial dos animais.
Durante o período experimental, a temperatura do ar da câmara foi regulada em $30^{\circ} \mathrm{C}$ e a umidade relativa em $75 \%$, sendo monitoradas diariamente, por meio de um conjunto de termômetros de bulbo seco e bulbo úmido e de globo negro. As dietas experimentais (Tabela 1) foram formuladas para atender as exigências nutricionais recomendadas por ROSTAGNO et al. (2005), exceto para os níveis energéticos. Os níveis de EL foram obtidos a partir da inclusão de óleo de soja em substituição ao caulim, mantendo o padrão de proteína ideal entre os tratamentos. As rações e a água foram fornecidas à vontade aos animais.

O experimento teve duração de 28 dias. Diariamente, foram coletados os resíduos de ração do chão, que foram somados às sobras do comedouro ao final do período experimental, determinando-se o consumo de ração diário (CRD). Os animais foram

Tabela 1 - Composições centesimais e nutricionais das dietas experimentais.

\begin{tabular}{|c|c|c|c|c|}
\hline \multirow{2}{*}{ Ingredientes } & \multicolumn{4}{|c|}{ - } \\
\hline & 2.300 & 2.424 & 2.548 & 2.668 \\
\hline Milho & 68,745 & 68,745 & 68,745 & 68,745 \\
\hline Farelo de soja (45\%) & 23,377 & 23,377 & 23,377 & 23,377 \\
\hline Óleo de soja & 0,000 & 1,684 & 3,368 & 5,000 \\
\hline Caulim & 5,000 & 3,316 & 1,632 & 0,000 \\
\hline Fosfato bicálcico & 0,815 & 0,815 & 0,815 & 0,815 \\
\hline Calcário & 0,541 & 0,541 & 0,541 & 0,541 \\
\hline Suplemento mineral $^{1}$ & 0,050 & 0,050 & 0,050 & 0,050 \\
\hline Suplemento vitamínico ${ }^{2}$ & 0,400 & 0,400 & 0,400 & 0,400 \\
\hline Sal comum & 0,356 & 0,356 & 0,356 & 0,356 \\
\hline L-Lisina $\mathrm{HCl}$ & 0,358 & 0,358 & 0,358 & 0,358 \\
\hline DL-Metionina & 0,127 & 0,127 & 0,127 & 0,127 \\
\hline L-Treonina & 0,132 & 0,132 & 0,132 & 0,132 \\
\hline Ractopamina $^{3}$ & 0,100 & 0,100 & 0,100 & 0,100 \\
\hline Total $(\mathrm{kg})$ & 100 & 100 & 100 & 100 \\
\hline Proteína bruta $(\%)$ & 16,70 & 16,70 & 16,70 & 16,70 \\
\hline Energia líquida $\left(\mathrm{kcal} \mathrm{kg}^{-1}\right)$ & 2.300 & 2.424 & 2.548 & 2.668 \\
\hline Energia metabolizável $\left(\mathrm{kcal} \mathrm{kg}^{-1}\right)$ & 3.072 & 3.237 & 3.402 & 3.563 \\
\hline Lisina total $(\%)$ & 1,100 & 1,100 & 1,100 & 1,100 \\
\hline Lisina digestível (\%) & 1,000 & 1,000 & 1,000 & 1,000 \\
\hline Met+Cist digestível (\%) & 0,617 & 0,617 & 0,617 & 0,617 \\
\hline Treonina digestível (\%) & 0,667 & 0,667 & 0,667 & 0,667 \\
\hline Triptofano digestível (\%) & 0,170 & 0,170 & 0,170 & 0,170 \\
\hline Valina digestível (\%) & 0,690 & 0,690 & 0,690 & 0,690 \\
\hline Cálcio $(\%)$ & 0,484 & 0,484 & 0,484 & 0,484 \\
\hline Fósforo total $(\%)$ & 0,440 & 0,440 & 0,440 & 0,440 \\
\hline Fósforo disponível (\%) & 0,248 & 0,248 & 0,248 & 0,248 \\
\hline Sódio (\%) & 0,160 & 0,160 & 0,160 & 0,160 \\
\hline
\end{tabular}

${ }^{1}$ Conteúdo por quilograma de produto: ferro, 100g; cobre, 10g; cobalto, 0,2g; manganês, 30g; zinco, 100g; iodo, 1,0g; selênio, 0,3g e excipiente q.s.p., $1000 \mathrm{~g} .{ }^{2}$ Conteúdo por quilograma de produto: Vit. A, 6.000.000UI; Vit. $\mathrm{D}_{3}, 1.000 .000 \mathrm{UI}$; Vit. E, 12.000UI; Vit. $\mathrm{B}_{1}, 0,5 \mathrm{~g}$; Vit. $\mathrm{B}_{2}, 2,6 \mathrm{~g}$; Vit. $\mathrm{B}_{6}, 0,7 \mathrm{~g}$; ácido pantotênico, $10 \mathrm{~g}$; Vit. $\mathrm{K}_{3}, 1,5 \mathrm{~g}$; ácido nicotínico, 22g; Vit. B12, 0,015g; ácido fólico, 0,2g; biotina, 0,05g; colina, $100 \mathrm{~g}$ e excipiente q.s.p., $1000 \mathrm{~g} .{ }^{3}$ Cloridrato de ractopamina a $2,05 \%$ em substituição ao caulim.

Ciência Rural, v.41, n.5, mai, 2011. 
pesados no início e no final do experimento para a determinação do ganho de peso diário (GPD) e da conversão alimentar (CA).

Aotérmino do experimento, os animais foram transportados para um frigorífico, onde permaneceram em baia de espera com acesso a água e sob jejum de sólidos por 10 horas. Previamente ao abate, os animais foram pesados. Ao final da linha de abate as carcaças foram pesadas para a determinação do peso de carcaça quente (PCQ) e rendimento de carcaça quente (RCQ). As carcaças foram divididas longitudinalmente $\mathrm{e}$ realizado corte na banda esquerda (no ponto $\mathrm{P} 2$ ) para a exposição do músculo Longissimus dorsi e do toucinho, onde foram determinadas a profundidade do músculo (PM), espessura de toucinho (ET) e a área de olho-de-lombo (AOL). O percentual de carne magra (CM) e a quantidade de carne na carcaça (QCC) foram determinados por meio de equações propostas por GUIDONI (2000), sendo:

Equação (1)

$\mathrm{CM}=65,92-0,685 \times \mathrm{xT}+0,094 \times \mathrm{PM}-0,026 \mathrm{xPCQ}$;

Equação (2)

$\mathrm{QCC}=7,38-0,48 \times \mathrm{xT}+0,059 \times \mathrm{PM}+0,525 \mathrm{xPCQ}$.

Os dados foram submetidos à análise de variância pelo procedimento GLM em nível de 5\% de significância. Os efeitos incluídos no modelo analítico foram ractopamina (Rac), níveis de EL e a interação entre ractopamina e EL ( $\left.\mathrm{Rac}^{*} \mathrm{EL}\right)$. As eventuais diferenças entre as médias para o fator ractopamina foram comparadas pelo Teste F. Os níveis de EL foram submetidos à análise de regressão. As análises estatísticas foram realizadas no programa computacional Statistical Analysis System (SAS, 2001).

\section{RESULTADOS E DISCUSSÃO}

Durante o período experimental, a temperatura ambiente da sala foi $29,5 \pm 2,3^{\circ} \mathrm{C}$, a umidade relativa do ar foi $89,0 \pm 7,2 \%$, a temperatura de globo negro foi $30,1 \pm 2,3^{\circ} \mathrm{C}$ e o ITGU calculado em $81,1 \pm 3,2$. A temperatura média do ambiente pode ser considerada como de estresse por calor para suínos em fase de terminação, por estar acima da temperatura crítica máxima de $27^{\circ} \mathrm{C}$ estabelecida para esta categoria (SAMPAIO et al., 2004).

Não houve interação $(\mathrm{P}>0,05)$ entre EL e ractopamina para as variáveis de desempenho (Tabela 2). Este resultado está de acordo com DUNSHEA et al. (1998) que não constataram interação entre níveis de energia digestível $\left(21,2 ; 24,7 ; 28,2 ; 32,7 ; 36,7 \mathrm{MJ} \mathrm{dia}^{-1} \mathrm{e}\right.$ a vontade) e a inclusão de $20 \mathrm{ppm}$ de ractopamina sobre o desempenho de suínos em terminação.

A ractopamina não afetou $(\mathrm{P}>0,05)$ o GPD e o CRD dos animais. Esse resultado é corroborado pelos

Tabela 2 - Desempenho de leitoas em terminação, sob estresse por calor, alimentadas com dietas contendo níveis de energia líquida (EL) e suplementadas com ractopamina ( $\mathrm{Rac})$.

\begin{tabular}{|c|c|c|c|c|c|c|c|c|c|c|}
\hline \multirow{2}{*}{ Variáveis } & \multirow{2}{*}{ Rac, ppm } & \multicolumn{4}{|c|}{----------Energia líquida (kcal kg-1 de ração)---------- } & \multirow{2}{*}{ Média } & \multicolumn{3}{|c|}{------------<P----------- } & \multirow{2}{*}{$\mathrm{CV}(\%)$} \\
\hline & & 2.300 & 2.424 & 2.548 & 2.668 & & $\mathrm{Rac}$ & EL & $\mathrm{Rac}^{*} \mathrm{EL}$ & \\
\hline \multirow{3}{*}{ PI ( $\mathrm{kg})$} & 0 & 69,42 & 69,30 & 69,20 & 69,27 & 69,30 & & & & \\
\hline & 20 & 69,28 & 68,45 & 69,24 & 69,17 & 69,06 & & & & \\
\hline & Média & 69,34 & 68,87 & 69,22 & 69,22 & 69,17 & 0,89 & 0,99 & 0,99 & 5,15 \\
\hline \multirow{3}{*}{$\mathrm{PF}(\mathrm{kg})$} & 0 & 87,00 & 88,27 & 86,35 & 89,05 & 87,67 & & & & \\
\hline & 20 & 92,52 & 88,60 & 87,44 & 89,35 & 89,53 & & & & \\
\hline & Média & 90,07 & 88,44 & 86,96 & 89,96 & 88,77 & 0,27 & 0,46 & 0,57 & 4,81 \\
\hline \multirow{3}{*}{ GDP (kg) } & 0 & 0,63 & 0,68 & 0,61 & 0,70 & 0,66 & & & & \\
\hline & 20 & 0,83 & 0,72 & 0,65 & 0,72 & 0,73 & & & & \\
\hline & Média & 0,74 & 0,69 & 0,63 & 0,71 & 0,69 & 0,16 & 0,34 & 0,49 & 18,97 \\
\hline \multirow{3}{*}{ CRD (kg) } & 0 & 1,70 & 1,66 & 1,66 & 1,66 & 1,67 & & & & \\
\hline & 20 & 1,75 & 1,58 & 1,59 & 1,64 & 1,64 & & & & \\
\hline & Média & 1,73 & 1,62 & 1,62 & 1,65 & 1,65 & 0,78 & 0,54 & 0,86 & 11,23 \\
\hline \multirow{3}{*}{$\mathrm{CA}\left(\mathrm{kg} \mathrm{kg}^{-1}\right)$} & 0 & 2,78 & 2,48 & 2,73 & 2,39 & $2,59^{\mathrm{a}}$ & & & & \\
\hline & 20 & 2,17 & 2,28 & 2,50 & 2,32 & $2,32^{\mathrm{b}}$ & & & & \\
\hline & Média & 2,45 & 2,38 & 2,60 & 2,36 & 2,45 & 0,05 & 0,45 & 0,51 & 15,31 \\
\hline
\end{tabular}


estudos de PEREIRA et al. (2008), CANTARELLI et al. (2009) e SANCHES et al. (2010) que, avaliando a suplementação de ractopamina para suínos em terminação, não observaram alterações no CRD. A consistência dos resultados nos estudos citados pode ser um indicativo de que a ractopamina não apresenta ação específica sobre o controle voluntário da ingestão de alimento nos suínos.

A inclusão de $20 \mathrm{ppm}$ de ractopamina melhorou $(\mathrm{P}<0,05)$ a CA dos animais em 10,4 em relação ao grupo controle. Efeitos positivos deste aditivo sobre a CA também foram relatados por SANCHES et al. (2010), que obtiveram melhora de aproximadamente $36 \%$ para suínos machos castrados submetidos a ambiente de estresse por calor em relação ao grupo não suplementado. A melhora observada sobre a CA no presente estudo pode ser justificada pelas modificações metabólicas geradas pela ractopamina sobre a composição do ganho de peso com provável aumento da deposição protéica em detrimento da deposição de gordura na carcaça, uma vez que o aumento da deposição de tecido proteico agrega mais moléculas de água $(1: 3,4)$ em relação à deposição de lipídios (HALAS et al., 2010), fato que pode resultar na melhora tanto do ganho quanto da eficiência alimentar.

Quanto à concentração energética das dietas, não foi constatado efeito $(P>0,05)$ dos níveis de EL sobre o GPD dos suínos. Da mesma forma, APPLE et al. (2004) relataram que o aumento da densidade energética da dieta não influenciou o GPD de suínos em terminação. Provavelmente, a resposta obtida para o GPD dos suínos no presente estudo pode ser justificada pela similaridade do resultado observado para o CRD dos animais entre os níveis de EL avaliados, fato que pode estar associado ao efeito depressor de consumo provocado pelas temperaturas ambientais elevadas às quais os animais foram submetidos no transcorrer do período experimental. Essa hipótese é corroborada por COLLIN et al. (2001), que constataram que os suínos expostos à alta temperatura ambiente reduzem significativamente o consumo de alimento para reduzir a produção total de calor corporal.

O CRD não diferiu $(\mathrm{P}>0,05)$ entre os níveis de EL avaliados. A resposta observada no presente estudo é corroborada pelos resultados de YI et al. (2010), que avaliaram níveis entre 2.250 e $2.640 \mathrm{kcal}^{\mathrm{de}} \mathrm{EL} \mathrm{kg}^{-1}$ de ração, com suínos em crescimento, e não constataram variação do consumo voluntário em função da variação energética. Por outro lado, os resultados obtidos no presente estudo também estão em discordância com os verificados por ETTLE et al. (2003) que, ao suplementar as dietas de suínos machos castrados e fêmeas, observaram redução do CRD quando o maior nível de energia (3.350 $\left.\mathrm{kcal}^{\mathrm{EM} \mathrm{kg}}{ }^{-1}\right)$ foi utilizado em relação ao menor nível energético (3.110 $\mathrm{kcal} \mathrm{EM} \mathrm{kg}^{-1}$ ).

Estas variações do CRD podem estar relacionadas aos ajustes da demanda energética dos animais, de forma que a baixa densidade energética das dietas é compensada com o aumento do consumo até que determinado nível de exigência de energia seja atingido (REZENDE et al., 2006). Provavelmente, no presente estudo, esta resposta não foi constatada, uma vez que os animais foram submetidos a temperaturas ambientais elevadas que podem ter deprimido a ingestão voluntária de alimento. ACA também não foi influenciada $(\mathrm{P}>0,05)$ pelos níveis de energia das dietas. Por outro lado, YI et al. (2010) observaram melhora na CA dos suínos, à medida que aumentou o nível energético da dieta (2.250 a $2.450 \mathrm{kcal}^{\mathrm{de}} \mathrm{EL} \mathrm{kg}{ }^{-1}$ ), sem, no entanto, observar variação sobre a ingestão de alimento.

Quanto às características de carcaça, foi observada interação $(P<0,05)$ entre os níveis de EL e ractopamina apenas para a ET, em que a inclusão de 20 ppm de ractopamina nas dietas contendo níveis energéticos mais elevados (2.548 e $2.668 \mathrm{kcal}$ EL) proporcionou redução $(\mathrm{P}<0,05)$ dos valores de ET. Por outro lado, a inclusão deste aditivo nas dietas contendo os demais níveis energéticos não influenciou $(\mathrm{P}>0,05)$ a ET dos animais. O mesmo foi constatado por WILLIAMS et al. (1994), que verificaram menor ET em suínos alimentados com dietas contendo ractopamina quando apresentaram baixos consumos de energia metabolizável. A partir dos resultados observados no presente estudo, pode-se inferir que a eficiência da ractopamina em reduzir a lipogênese no tecido adiposo do suíno é mais pronunciada nas situações em que as dietas apresentam maior conteúdo energético, principalmente sob a forma de lipídios.

O PCQ não foi influenciado $(\mathrm{P}>0,05)$ pela inclusão de ractopamina na dieta, o que está coerente com a resposta observada para o peso final dos animais. Porém, ARMSTRONG et al. (2004) verificaram melhora nesta variável com a suplementação de 5, 10 ou 20ppm de ractopamina em relação à dieta controle.

Não foi constatado efeito $(\mathrm{P}>0,05)$ da ractopamina sobre a $\mathrm{AOL}, \mathrm{PM}$ e comprimento de carcaça (CC). Os níveis de EL não influenciaram ( $\mathrm{P}>0,05) \mathrm{oPCQ}$, PM, CC, AOL e o RCQ das leitoas em terminação (Tabela 3). Houve interação $(\mathrm{P}<0,05)$ entre níveis de EL e ractopamina para a $\mathrm{CM}$. Constatou-se que a inclusão de $20 \mathrm{ppm}$ de ractopamina em dietas contendo $2.548 \mathrm{e}$ $2.668 \mathrm{kcal}^{\mathrm{de}} \mathrm{EL} \mathrm{\textrm {kg } ^ { - 1 }}$ de ração proporcionou aumento $(\mathrm{P}<0,01)$ desta variável em relação àquelas alimentadas com a dieta sem inclusão de ractopamina.

Ciência Rural, v.41, n.5, mai, 2011. 
Tabela 3 - Características de carcaça de leitoas em terminação, sob estresse por calor, alimentadas com dietas contendo níveis de energia líquida (EL) e suplementadas com ractopamina (Rac).

\begin{tabular}{|c|c|c|c|c|c|c|c|c|c|c|}
\hline \multirow{2}{*}{ Variáveis } & \multirow{2}{*}{ Rac, ppm } & \multicolumn{4}{|c|}{-------Energia líquida (kcal kg ${ }^{-1}$ de ração) -------- } & \multirow[b]{2}{*}{ Média } & \multicolumn{3}{|c|}{ 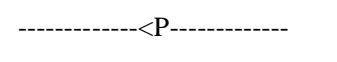 } & \multirow{2}{*}{$\mathrm{CV}(\%)$} \\
\hline & & 2.300 & 2.424 & 2.548 & 2.668 & & Rac & EL & $\mathrm{Rac}^{*} \mathrm{EL}$ & \\
\hline \multirow{3}{*}{ PCQ (kg) } & 0 & 69,55 & 69,05 & 67,55 & 70,72 & 69,22 & \multirow{4}{*}{0,19} & \multirow{4}{*}{0,60} & \multirow{4}{*}{0,78} & \multirow[b]{3}{*}{5,42} \\
\hline & 20 & 72,14 & 69,12 & 71,14 & 71,62 & 71,08 & & & & \\
\hline & Média & 70,99 & 69,09 & 69,54 & 71,17 & 70,18 & & & & \\
\hline \multirow{3}{*}{$\mathrm{ET}(\mathrm{mm})$} & $0 *$ & $5,75^{\mathrm{a}}$ & $4,50^{\mathrm{a}}$ & $7,75^{\mathrm{a}}$ & $8,25^{\mathrm{a}}$ & 6,56 & & & & \\
\hline & $20^{\mathrm{ns}}$ & $4,60^{\mathrm{a}}$ & $5,75^{\mathrm{a}}$ & $3,60^{\mathrm{b}}$ & $5,50^{\mathrm{b}}$ & 4,78 & \multirow[b]{2}{*}{0,01} & \multirow[b]{2}{*}{0,03} & \multirow[b]{2}{*}{0,01} & \multirow[b]{2}{*}{21,21} \\
\hline & Média & 5,11 & 5,12 & 5,44 & 6,87 & 5,65 & & & & \\
\hline \multirow{3}{*}{ PM (mm) } & 0 & 62,75 & 62,25 & 61,00 & 60,25 & 61,56 & \multirow[b]{3}{*}{0,57} & \multirow[b]{3}{*}{0,97} & \multirow[b]{3}{*}{0,70} & \multirow[b]{3}{*}{7,90} \\
\hline & 20 & 60,40 & 62,50 & 60,80 & 64,50 & 61,89 & & & & \\
\hline & Média & 61,44 & 62,37 & 60,89 & 62,37 & 61,75 & & & & \\
\hline \multirow{3}{*}{$\mathrm{CC}(\mathrm{cm})$} & 0 & 93,50 & 89,00 & 88,12 & 94,00 & 91,16 & \multirow[b]{3}{*}{0,84} & \multirow[b]{3}{*}{0,12} & \multirow[b]{3}{*}{0,38} & \multirow[b]{3}{*}{3,42} \\
\hline & 20 & 92,20 & 89,75 & 91,20 & 92,25 & 91,39 & & & & \\
\hline & Média & 92,80 & 89,37 & 89,83 & 93,12 & 91,28 & & & & \\
\hline \multirow{3}{*}{$\mathrm{AOL}\left(\mathrm{cm}^{2}\right)$} & 0 & 45,02 & 43,00 & 41,92 & 39,55 & 42,37 & \multirow[b]{3}{*}{0,75} & \multirow[b]{3}{*}{0,94} & \multirow[b]{3}{*}{0,22} & \multirow[b]{3}{*}{12,55} \\
\hline & 20 & 40,72 & 40,70 & 44,96 & 45,45 & 42,94 & & & & \\
\hline & Média & 42,63 & 41,85 & 43,61 & 42,50 & 42,65 & & & & \\
\hline & 0 & 84,75 & 81,69 & 82,16 & 82,55 & 82,79 & & & & \\
\hline RCQ (\%) & 20 & 81,60 & 82,46 & 85,64 & 83,38 & 83,31 & & & & \\
\hline & Média & 82,99 & 82,08 & 84,09 & 82,97 & 83,04 & 0,60 & 0,66 & 0,28 & 4,19 \\
\hline & $0 *$ & $69,69^{\mathrm{a}}$ & $70,48^{\mathrm{a}}$ & $69,10^{\mathrm{b}}$ & $67,77^{\mathrm{b}}$ & 69,01 & & & & \\
\hline $\mathrm{CM}(\%)$ & $20^{\mathrm{ns}}$ & $70,32^{\mathrm{a}}$ & $69,65^{\mathrm{a}}$ & $71,01^{\mathrm{a}}$ & $70,08^{\mathrm{a}}$ & 70,31 & & & & \\
\hline & Média & 70,04 & 70,07 & 69,72 & 68,93 & 69,68 & 0,01 & 0,04 & 0,01 & 1,07 \\
\hline & 0 & 44,79 & 45,11 & 42,67 & 44,05 & $44,16^{b}$ & & & & \\
\hline QCC (kg) & 20 & 46,58 & 44,56 & 46,56 & 46,11 & $46,02^{\mathrm{a}}$ & & & & \\
\hline & Média & 45,78 & 44,83 & 44,83 & 45,08 & 45,11 & 0,01 & 0,70 & 0,13 & 4,03 \\
\hline
\end{tabular}

PCQ (peso de carcaça quente); ET (espessura de toucinho); PM (profundidade de músculo); CC (comprimento de carcaça); AOL (área de olho-de-lombo); RCQ (rendimento de carcaça quente); CM (percentual de carne magra); QCC (quantidade de carne na carcaça).

Médias nas colunas seguidas por letras distintas entre linhas diferem, em nível de 5\% de significância, pelo teste $\mathrm{F}$; *Efeito quadrático $(\mathrm{P}<0,05) ; * *$ Efeito linear $(\mathrm{P}<0,05) ;{ }^{\text {ns }}$ efeito não significativo $(\mathrm{P}>0,05)$.

ET 0ppm: $Y=171,39073-0,14194 x+0,00003033 x^{2}, r^{2}=0,72 ; C M, \% 0 p p m: Y=-35,1783+0,09082 x-0,000019 x^{2} ; r^{2}=0,94$.

De acordo com WILLIAMS et al. (1994), leitoas alimentadas com dieta sem ractopamina apresentaram melhora na percentagem de carne magra até o consumo de $8,9 \mathrm{Mcal}$ de energia metabolizável dia $^{-1}$, todavia o aumento da ingestão energética não resultou em melhora da deposição de carne magra. Porém, APPLE et al. (2004) concluíram que o aumento da $\mathrm{CM}$ em suínos alimentados com dietas contendo ractopamina exige aumento da concentração energética da dieta, fato que contraria os resultados do presente estudo.

A QCC das leitoas diferiu $(\mathrm{P}<0,05)$ em função da inclusão de ractopamina na dieta, sendo observado aumento de $4 \%$ nas fêmeas suplementadas com o aditivo. Um dos efeitos mais conhecidos da ractopamina em suínos é o incremento da massa muscular com aumento da QCC. Uma das explicações é que este composto liga-se aos receptores de membranas e dispara uma série de eventos que levam ao aumento no diâmetro das fibras musculares, mais especificamente das fibras brancas e intermediárias (SEE et al., 2004).

Além disso, o efeito da ractopamina sobre a melhora das características quantitativas da carcaça é mais pronunciado com o aumento da idade e do peso dos suínos. Essa hipótese é confirmada por CROME et 
al. (1996), que constataram que a ractopamina foi mais eficaz em melhorar o desempenho e as características de carcaça quando administrada a suínos pesados ( 85 aos $125 \mathrm{~kg}$ ) em relação aos leves (68 aos $107 \mathrm{~kg})$. Nos suínos mais pesados, a deposição de lipídios na carcaça tende a aumentar numa proporção maior em relação a deposição de proteína (WHITTEMORE, 1998), fato que pode aumentar a eficiência de ação da ractopamina em bloquear parcialmente a lipogênese.

O RCQ dos animais não foi influenciado $(\mathrm{P}>0,05)$ pela inclusão de ractopamina e pelos níveis de EL das dietas. Em contraste, PEREIRA et al. (2008) observaram aumento de 3,9\% no RCQ de leitoas em terminação, recebendo 5ppm de ractopamina. A partir dos resultados obtidos no presente estudo, pode-se inferir que os efeitos esperados da ractopamina sobre as características de carcaças das leitoas, mesmo sendo sob temperaturas ambientais elevadas, estão coerentes com a literatura, uma vez que houve redução da deposição de gordura na carcaça, fato confirmado pela menor ET. Além disso, houve aumento da deposição de proteína confirmada pelos aumentos da CM e da QCC.

\section{CONCLUSÃO}

Independentemente do nível energético, a suplementação de 20ppm de ractopamina na dieta de leitoas melhora a CA e aumenta a QCC nas carcaças. A ractopamina é mais efetiva na redução da ET em dietas contendo níveis energéticos elevados (2.548 e $2.668 \mathrm{kcal}$ de EL).

\section{AGRADECIMENTO}

À Fundação de Apoio ao Desenvolvimento do Ensino, Ciência e Tecnologia do Estado de Mato Grosso do Sul (FUNDECT), pelas bolsas de Mestrado concedidas a Mariana Souza de Moura e Alexandre Pereira dos Santos.

\section{REFERÊNCIAS}

ALMEIDA, E.C. et al. Digestibilidade ileal e perdas endógenas de aminoácidos de dietas com óleo de soja para suínos em crescimento. Revista Brasileira de Zootecnia, v.36, p.1045-1051, 2007. Disponível em: <http://www.scielo.br/ scielo.php? script=sci_arttext \& pid=S 1516 35982007000500009>. Acesso em: 05 set. 2010. doi: 10.1590/S1516-35982007000500009.

APPLE, J.K. et al. Effects of dietary lysine and energy density on performance and carcass characteristics of finishing pigs fed ractopamine. Journal of Animal Science, v.82, p.32773287, 2004. Disponível em: <http://jas.fass.org/cgi/reprint/ 82/11/3277>. Acesso em: 12 ago. 2010.

ARMSTRONG, T.A. et al. The effect of dietary ractopamine concentration and duration of feeding on growth performance, carcass characteristics, and meat quality of finishing pigs.
Journal of Animal Science, v.82, p.3245-3253, 2004. Disponível em: <http://jas.fass.org/cgi/reprint/82/11/3245>. Acesso em: 25 ago. 2010.

CANTARELLI, V.S. et al. Características da carcaça e viabilidade econômica do uso de cloridrato de ractopamina para suínos em terminação com alimentação à vontade ou restrita. Ciência Rural, v.39, p.844-851, 2009. Disponível em: <http://www.scielo.br/pdf/cr/v39n3/a32v39n3.pdf>. Acesso em: 12 ago. 2010. doi: 0.1590/S0103-84782009000300032.

COLLIN, A. et al. Effect of high temperature and feeding level on energy utilization in piglets. Journal of Animal Science, v.79, p.1849-1857, 2001. Disponível em: <http://jas.fass.org/ cgi/reprint/79/7/1849>. Acesso em: 25 ago. 2010.

CROME, P.K. et al. Effect of ractopamine on growth performance, carcass composition, and cutting yields of pigs slaughtered at 107 and 125 kilograms. Journal of Animal Science, v.74, p.709-716, 1996. Disponível em: <http:// jas.fass.org/cgi/reprint/74/4/709.pdf>. Acesso em: 25 ago. 2010.

DUNSHEA, F.R. et al. Interrelationships between dietary ractopamine, energy intake, and sex in pigs. Australian Journal Agriculture Research, v.49, p.565-574, 1998. Disponível em: <http://www.publish.csiro.au/?paper=A97106>. Acesso em: 25 ago. 2010. doi: 10.1071/A97106.

ETTLE, J. et al. Effect of apparent ileal digestible lysine to energy ratio on performance of finishing pigs at different dietary metabolizable energy levels. Journal of Animal Physiology and Animal Nutrition, v.87, p.269-279, 2003. Disponível em: <http://onlinelibrary.wiley.com/doi/10.1046/ j.1439-0396.2003.00436.x/full>. doi: 10.1046/j.14390396.2003.00436.x.

GUIDONI, A.L. Melhoria de processos para a tipificação e valorização de carcaças suínas no Brasil. In: CONFERÊNCIA INTERNACIONAL VIRTUAL SOBRE QUALIDADE DE CARNE SUÍNA, 2000, Concórdia, SC. Anais... Concórdia, 2000. p.14. Disponível em: <http://www.cnpsa.embrapa.br/ sgc/sgc_publicacoes/anais00cv_guidoni_pt.pdf $>$. Acesso em: 26 nov. 2009.

HALAS, V. et al. Efficiency of fat deposition from nonstarch polysaccharides, starch and unsaturated fat in pigs. British Journal of Nutrition, v.103, p.123-133. 2010. Disponível em: <http://journals.cambridge.org/ download.php?file=\%2FBJN\%2FBJN103_01\%2FS00071145099914 49a.pdf \& $\operatorname{code}=\mathrm{dc} 2 \mathrm{f} 47 \mathrm{bc} 41438 \mathrm{e} 3 \mathrm{f} 15 \mathrm{bc} 15 \mathrm{f} 69 \mathrm{c} 7 \mathrm{fae} 16>$. Acesso em: 25 ago. 2010. doi: 10.1017/S0007114509991449.

KERR, B.J. et al. Influences of dietary protein level, amino acid supplementation and environment temperature on performance, body composition, organ weights and total heat production of growing pigs. Journal of Animal Science, v.81, p.1998-2007, 2003. Disponível em: <http://jas.fass.org/ cgi/reprint/81/8/1998>. Acesso em: 25 ago. 2010.

MOREIRA, I. et al. Efeitos da restrição energética para suínos na fase final de terminação sobre o desempenho, característica de carcaça e poluição ambiental. Acta Scientiarum Animal Science, v.29, p.179-185, 2007. Disponível em: <http:// periodicos.uem.br/ojs/index.php/ActaSciAnimSci/article/view/ 223/175>. Acesso em: 25 ago. 2010. 
PEREIRA, F.A. et al. Efeitos da ractopamina e de dois níveis de lisina digestível na dieta sobre o desempenho e características de carcaça de leitoas em terminação. Arquivo Brasileiro de Medicina Veterinária e Zootecnia, v.60, p.943-952, 2008. Disponível em: <http://www.scielo.br/pdf/abmvz/v60n4/ 25.pdf $>$. Acesso em: 25 ago. 2010. doi: 10.1590/S010209352008000400025 .

PÉREZ, A. et al. Efectos de la ractopamina y lisina sobre la deposición de grasa en cerdos seleccionados magros en la fase de engorde. Zootecnia Tropical, v.24, n.4, p.435455, 2006. Disponível em: <http://www.scielo.org.ve/ s cielo.php ? script $=$ sci_art text \& pid=S 0798 $72692006000400004 \& \operatorname{lng}=\mathrm{es} \& \mathrm{nrm}=\mathrm{iso}>$. Acesso em: 25 ago. 2010 .

REZENDE, W.O. et al. Níveis de energia metabolizável mantendo a relação lisina digestível:caloria em rações para suínos machos castrados em terminação. Revista Brasileira de Zootecnia, v.35, p.1101-1106, 2006. Disponível em: <http:/ /www.scielo.br/pdf/rbz/v35n3s0/30723.pdf>. Acesso em: 25 ago. 2010. doi: 10.1590/S1516-35982006000400022.

ROSTAGNO, H.S. et al. Tabelas brasileiras para aves e suínos: composição de alimentos e exigências nutricionais. 2.ed. Viçosa: UFV, 2005. $186 \mathrm{p}$.

SAMPAIO, C.A.P. et al. Avaliação do ambiente térmico em instalações para crescimento e terminação de suínos utilizando os índices de conforto térmico nas condições tropicais. Ciência Rural, v.34, p.785-790, 2004. Disponível em: <http:// www.scielo.br/pdf/cr/v34n3/a20v34n3.pdf >. Acesso em: 25 ago. 2010. doi: 10.1590/S0103-84782004000300020.
SANCHES, J.F. et al. Níveis de ractopamina para suínos machos castrados em terminação mantidos sob estresse por calor. Revista Brasileira de Zootecnia, v.39, p.1523-1529, 2010. Disponível em: <http://www.scielo.br/pdf/rbz/v39n7/ a19v39n7.pdf>. Acesso em: 25 ago. 2010. doi: 10.1590/ S1516-35982010000700019.

SAS. User's guide, version 7, 5.ed. North Caroline, 2001. $1686 \mathrm{p}$.

SEE, M.T. et al. Effect of a ractopamina feeding program on growth performance and carcass composition in finishing pigs. Journal of Animal Science, v.82, p.2474-2480, 2004. Disponível em: <http://jas.fass.org/cgi/reprint/82/8/2474.pdf>. Acesso em: 26 ago. 2010.

WHITTEMORE, C. The science and practice of pig production. 2.ed. London, UK: Blackwell Science, 1998. 624p.

WILLIAMS, N.H. et al. The impact of ractopamine, energy intake, and dietary fat on finishing pig growth performance and carcass merit. Journal of Animal Science, v.72, p.31523162, 1994. Disponível em: <http://jas.fass.org/cgi/reprint/ 72/12/3152>. Acesso em: 25 ago. 2010.

YI, X.W et al. Influence of dietary net energy content on performance of growing pigs fed low crude protein diets supplemented with crystalline amino acids. Journal of Swine Health and Production, v.18, p.294-300, 2010. Disponível em: <http://www.aasv.org/shap/issues/v18n6/v18n6p294.pdf>. Acesso em: 25 ago. 2010. 